\title{
O papel do item lexical e da estrutura social na direcionalidade da mudança sonora
}

\section{The role of lexical item and social structure in the directionality of sound change \\ Marcelo Alexandre Silva Lopes Melo¹, Christina Abreu Gomes²}

Doutorando do Programa de Pós-graduação em Linguística da Universidade Federal do Rio de Linguística e Filologia da UFR.

E-mail: malmelo@globo.com

Doutora em Linguística, UFRJ, Professora Titular do Departamento de Linguistica e Filologia, Bolsista de Produlivida em Pesquisa/CNPq.
RESUMO: A hipótese segundo a qual falantes estabelecem representações detalhadas dos itens lexicais baseadas nas suas experiências com o uso, relativas à produção e percepção, situa a variação sonora no plano representacional, possibilitando novas abordagens sobre a dinâmica sociolinguística de uma comunidade de fala (GOMES e SILVA, 2004; FOULKES e DOCHERTY, 2006). Este artigo compara o comportamento de dois grupos sociais da comunidade de fala do Rio de Janeiro em relação à variação da fricativa em coda: a) adolescentes moradores de favelas que diferem em termos de integração social (amostras EJLA e Fiocruz); b) subgrupo de falantes da classe média (amostra Censo 2000). 0 comportamento de falantes socialmente excluídos pode contribuir para a compreensão da dinâmica sociolinguística da comunidade de fala, especialmente em se tratando de adolescentes, os quais representam um grupo importante na delimitação e expansão do significado social de variantes e na propagação da mudança linguística (ECKERT, 1989, 2000; WAGNER, 2008). Os resultados observados revelam que o grau de integração de jovens socialmente excluídos pode afetar o comportamento linguístico deste grupo, bem como evidenciam a importância do item lexical para detectar se há diferentes direcionalidades de mudança entre grupos sociais de uma mesma comunidade de fala para variáveis sociofonéticas.

PalavraS-CHAVE: Mudança sonora; Condicionamento fonético; Item lexical.

ABSTRACT: The hypothesis that speakers establish detailed representations of lexical items based on their experience with the use - production and perception - located the sound variation in representational plan, enabling new approaches to the sociolinguistic dynamics of a speech community (GOMES and SILVA, 2004; FOULKES and DOCHERTY, 2006). This article compares the behavior of two social groups of the speech community of Rio de Janeiro in relation to the variation of fricative in coda: a) adolescents living in slums that differ in terms of social integration (EJLA and Fiocruz samples); b) subgroup of middle class speakers (Census 2000 sample). The behavior of socially excluded speakers can contribute to the understanding of the sociolinguistic dynamics of the speech community, especially when it comes to teenagers, which represent an important group in the delineation and expansion of the social significance of variants and propagation of linguistic change (ECKERT, 1989, 2000; WAGNER, 2008). These results show that the degree of integration of socially excluded adolescents can affect the linguistic behavior of this group and show the importance of lexical items to detect whether there are different directionality of linguistic change among social groups of one speech community to sociophonetic variables.

KEYworDS: Sound change; Phonetic constrain; Lexical item. 


\section{Introdução}

$\mathrm{E}^{\mathrm{se}}$ te artigo apresenta resultados de um estudo que observa o comportamento de dois grupos de adolescentes da comunidade de fala do Rio de Janeiro, moradores de favela ${ }^{1}$, que diferem em termos de integração social (estrutura familiar, grau de escolarização e acesso a programas sociais de educação) em duas diferentes amostras: a) a amostra EJLA (PEUL/UFRJ), constituída por adolescentes que viviam em uma unidade de internação em razão de terem cometido atos infracionais; b) a amostra Fiocruz (PEUL/UFRJ), constituída por adolescentes que participavam de um curso oferecido por uma renomada instituição de ensino e pesquisa do país. O comportamento desses dois grupos foi também observado em relação a resultados obtidos para falantes da amostra Censo 2000 (PEUL/UFRJ). A comparação do comportamento dos dois grupos de adolescentes com um subgrupo de falantes da classe média pertencentes à amostra Censo 2000 teve como objetivo captar a dinâmica sociolinguística da comunidade de fala do Rio de Janeiro de forma mais ampla com a inclusão de segmentos sociais normalmente excluídos de amostras dos estudos sociolinguísticos.

Entende-se que o grau de integração social de falantes socialmente excluídos - moradores de favelas do Rio de Janeiro - pode afetar o comportamento linguístico deste grupo. Além disso, o estudo teve também como objetivo buscar evidências mais robustas acerca da relação entre

\footnotetext{
${ }^{1}$ Conforme Birman (2008), o termo comunidade vem sendo adotado - pelo senso comum, grande mídia e agentes políticos - como um eufemismo para designar grupos de pessoas que vivem em territórios socialmente vulneráveis, nos quais a violência e exclusão social estão mais diretamente associados. 0
uso do termo comunidade tem por fim remover os traços estigmatizantes que pesam sobre o uso da uso do termo comunidade tem por fim remover os traços estigmatizantes que pesam sobre o uso da palavra favela, mas, conforme adverte a autora, "não é capaz de impedir a associação da pessoa com traços negativos provenientes dessa identificação; somente indica a suspensão destes pelo uso de aspas que podem ser retiradas quando for preciso" (p. 107). Assim, como aponta a autora, é fundamental não remover ou substituir a palavra favela, mas sim ultrapassar - e ressignificar - a identidade desses
espaços e de seus moradores.
}

condicionamentos fonéticos e o papel do item lexical na propagação da mudança sonora, uma vez que os resultados encontrados em Melo (2012) mostraram que, para detectar se há diferentes direcionalidades de mudança entre grupos sociais de uma mesma comunidade de fala, é preciso levar em conta o comportamento de itens lexicais na variação sonora juntamente com variáveis estruturais.

Assim, este artigo também pretende contribuir com evidências para a discussão teórica relativa à abordagem da variação sociolinguística por regras ou processos (rule-based) ou restrições e a abordagem baseada no uso (usage-based), que confere um caráter representacional à variação (DOCHERTY e FOULKES, 2014; HINSKENS, BERMANS, OOSTENDORP, 2014). A abordagem da variação sonora baseada em regras e restrições tem sido a predominante nos estudos sociolinguísticos, no entanto, recentemente, o comportamento específico de itens lexicais tem sido observado, assim como a importância do detalhe fonético, e o caráter representacional da variação tem sido considerado na explicação da variação sonora (BYBEE, 2002; FOULKES e DOCHERTY, 2006).

A realização da fricativa em posição de coda silábica - como em me[3]mo $\sim$ me[z]mo $\sim$ me[h]mo $\sim$ me[0]mo - é uma variável largamente estudada do Português Brasileiro (CALLOU e MORAES, 1996; RONCARATI, 1999) em diferentes comunidades de fala, como em Salvador (CANOVAS, 1991; MOTA, 2002), Recife (MACEDO, 2004), Santa Catarina (BRESCANCINI, 1996) e diferentes cidades do estado do Rio de Janeiro (GRYNER e MACEDO, 2000; SANTOS, 2009). Da mesma forma, a variação da fricativa em coda já foi objeto de análise de diversos estudos na comunidade de fala da cidade do Rio de Janeiro (CALLOU e MARQUES, 1975; GUY, 1981; AULER, 1992; SCHERRE e MACEDO, 2000). O conjunto de resultados obtidos nos diferentes trabalhos até o momento permite traçar um perfil sociolinguístico mais completo da dinâmica desta variável na comunidade de fala do Rio de Janeiro com 
contribuições tanto para o entendimento desta variável especificamente quanto para as questões teóricas mais amplas mencionadas anteriormente.

Serão apresentados a seguir, na seção 2 , os conceitos principais que sustentam a abordagem adotada neste estudo: o de variação como representação, de acordo com os Modelos baseados no Uso, bem como a questão da definição de comunidade de fala e do papel dos adolescentes na propagação da mudança linguística. A seção 3 contém uma breve descrição das amostras em estudo. As seções 4 e 5, respectivamente, tratam da análise dos dados obtidos e considerações finais.

\section{Pressupostos teóricos}

Weinreich, Labov e Herzog (1968, p.126) mencionaram a importância das contribuições da Linguística teórica para o entendimento da variação e da mudança linguística ${ }^{2}$. Assim, o tratamento representacional dado à variabilidade observada na fala pelos Modelos baseados no Uso pode trazer novas contribuições para a compreensão da natureza do conhecimento linguístico do falante. Nesta abordagem, a representação detalhada é captada pela Teoria de Exemplares.

Primeiramente introduzida na Psicologia como um modelo de percepção e categorização, a Teoria de Exemplares foi trazida para a Linguística para análise dos sons da fala por Johnson (1996). A Teoria de Exemplares, ao postular que a estrutura do conhecimento linguístico é construída pela representação na memória da totalidade de experiências linguísticas

2 "In relation to language change, each refinement in the theory of language structure (and the same could be said about refinements in the theory of speech communities) had the following potential effects:

(a) a reclassification of observed changes according to new principles;

(b) proposal of fresh constraints on change; and

(c) proposal of new causes of change." vivenciadas pelo indivíduo, oferece a hipótese de representação para que a modelagem da variabilidade seja construída. De acordo com a Teoria de Exemplares, a representação do padrão sonoro de um determinado item lexical não é reduzida apenas às informações distintivas dos segmentos que constituem este item, mas consiste no registro detalhado da experiência do indivíduo em ouvir e produzir o item (GOMES e SILVA, 2004; FOULKES e DOCHERTY, 2006).

Dessa forma, a representação lexical inclui características articulatórias e acústicas detalhadas que se baseiam na experiência do indivíduo com a língua em diversas situações de uso, envolvendo, portanto, produção e percepção. Ainda de acordo com a Teoria de Exemplares, estão representadas informações linguísticas detalhadas, como também informações de indexação social de várias naturezas (classe social, gênero/sexo, variedade regional, idade, entre outras) (FOULKES e DOCHERTY, op. cit.).

Ao incorporarem a Teoria de Exemplares como modelo de representação, os Modelos Baseados no Uso (doravante MBU) assumem a hipótese de que a estocagem é redundante, ou seja, todas as ocorrências de uso percebidas e produzidas são armazenadas no léxico. As formas detalhadas armazenadas no léxico representam diretamente a variação encontrada no uso. Em outras palavras, as formas sonoras dos itens lexicais estão representadas no léxico e constituem generalizações a partir da fala. A partir das representações detalhadas emergem outros tipos de representação de diferentes graus de abstração (BYBEE, 2001; 2010; PIERREHUMBERT 2003; 2016).

Os Modelos baseados no Uso postulam que as representações mais abstratas emergem das formas das palavras representadas no léxico. Além disso, postula-se que os itens lexicais estão organizados em redes lexicais baseadas nas similaridades sonoras e semânticas entre as palavras (BYBEE, 2001, 2010; PIERREHUMBERT, 2003, 2016) e não em uma lista não estruturada. As representações são estáveis e dinâmicas, pois a experiência 
com o uso leva à consolidação das representações (entrenchment), ao mesmo tempo em que são atualizadas pela experiência com o uso que tanto pode reforçar características articulatórias e acústicas recorrentes como acrescentar novas.

As teorias clássicas assumem que a representação dos itens lexical exclui o detalhe fonético, constituindo uma representação única subjacente, baseada no conceito de fonema, unidade abstrata que exclui todas as informações redundantes e contém somente aquelas com função distintiva. Por outro lado, os MBU postulam que a gramática fonológica - padrões fonológicos recorrentes no léxico, relações fonotáticas e relações morfossintáticas entre os itens lexicais - é emergente das representações fonéticas detalhadas das palavras no léxico (PIERREHUMBERT, 2003; 2016).

Se a experiência de ouvir e produzir afeta a representação, a frequência de ocorrência dos itens lexicais tem consequências na estocagem (BYBEE, 2001; 2010). De acordo com Bybee (2001:10), existem dois tipos de frequência a serem considerados: frequência de ocorrência (token frequency) e frequência de tipo (type frequency). A frequência de ocorrência é determinada pela quantidade de vezes em que uma unidade (palavra, estrutura silábica, unidade sonora, por exemplo) é encontrada em um determinado corpus. Já a frequência de tipo é determinada pela frequência de um padrão no léxico. Tanto a frequência de tipo quanto a frequência de ocorrência atuam como mecanismos de propagação da mudança (BYBEE, 2010; 2012).

Há diversas evidências na literatura que apontam para o fato de que mudanças sonoras que apresentam condicionamento fonético tendem a afetar primeiramente os itens lexicais mais frequentes. A razão está no fato de que qualquer modificação motivada foneticamente ocorre no momento da articulação propriamente dita, através da redução de gestos articulatórios ou de coarticulações, ou seja, essas modificações ocorrem no momento da produção. Assim, quanto mais usado o item, mais sujeito a estar submetido a essas mudanças. Por outro lado, palavras com alta frequência de ocorrência tendem a ter uma representação robusta no léxico e, por isso, sua representação é forte, estando menos sujeitas a mudanças analógicas que envolvem categorias mais abstratas.

Outro conceito importante é o de comunidade de fala. $O$ conceito de comunidade de fala, cunhado a partir da década de 1960 por Labov, influenciou sobremaneira os estudos sociolinguísticos ao propor que o estudo da estrutura e evolução da língua deveria se dar dentro do contexto social da comunidade de fala. Para Labov, se a língua é um sistema heterogêneo, a comunidade de fala apresenta certa homogeneidade, a qual é garantida pelos padrões estruturais e pelas atitudes linguísticas compartilhadas pelos membros de determinada comunidade. Os indivíduos de uma mesma comunidade de fala, segundo Labov, compartilham as mesmas normas linguísticas, incluindo os mesmos valores e atitudes sobre as formas linguísticas em uso. Labov postula ainda que os limites entre comunidades de fala se fundamentam no sistema linguístico abstrato dos falantes e de suas atitudes sociais em relação à língua (LABOV, 1972), hipótese esta reforçada por Guy (2001).

De acordo com o conceito de comunidade de fala defendido por Labov e Guy, o indivíduo não é autônomo em relação à comunidade de fala à qual pertence: os indivíduos apenas replicam - em maior ou menor grau - os padrões linguísticos estabelecidos por seus pares. Não se trata de negar a gramática de cada falante, mas sim entender que a gramática do falante depende das gramáticas dos indivíduos que o cercam. Nesse sentido, é importante considerar a interação entre o falante e a sociedade em que se encontra inserido ${ }^{3}$.

No entanto, o conceito de comunidade de fala formulado por Labov tem sido questionado nos estudos sociolinguísticos, principalmente no que se refere ao fato de indivíduos de diferentes classes sociais compartilharem

Patrick (2002) apresenta uma discussão ampla do conceito de comunidade de fala na literatura Sociolinguística. 
as mesmas avaliações sobre as formas linguísticas em uso. Naro \& Scherre (1991, p. 09), defendem que "a comunidade de fala pode estar caminhando em diversas direções, no sentido que alguns grupos de falantes podem estar num processo de aquisição de uma forma enquanto outros estão, ao mesmo tempo, perdendo a forma". Em outras palavras, os referidos autores assumem que uma forma linguística pode seguir direções diferentes dentro de uma mesma comunidade de fala, o que estabelece um desafio ao conceito de valores uniformemente compartilhados de Labov.

Também o papel que o indivíduo exerce sobre a variação é objeto de discussão na literatura sobre o assunto. De uma maneira geral, Gomes (2011) observa que o papel do indivíduo na variação é visto em função da relação entre o indivíduo e a comunidade de fala em que se encontra inserido. Assim, Gomes (op. cit.) afirma que há estudos que apontam para o fato de as variáveis independentes analisadas atuarem da mesma maneira para os indivíduos de uma mesma comunidade de fala, mesmo que haja diferenças nas médias individuais. Porém, ainda de acordo com Gomes (op. cit.), há estudos que apontam para o fato de os indivíduos não apresentarem a mesma regularidade esperada para a comunidade de fala em que se inserem (GOMES e PAIVA, 2002; PAIVA e DUARTE, 2003).

A definição clássica para o conceito de comunidade de fala postulado por Labov conduz a uma questão: se os indivíduos podem seguir padrões distintos daquele observado pela comunidade e se grupos de uma mesma comunidade podem apresentar padrões diferentes, será que a avaliação social das formas linguísticas é a mesma para todos os falantes? Em outras palavras, todos os falantes fazem a mesma avalição das formas linguísticas observadas em uma mesma comunidade de fala? Se a resposta for negativa, então, verifica-se a necessidade de extensão do conceito de comunidade de fala formulado por Labov, uma vez que todos os falantes não compartilhariam os mesmos valores sociais que são atribuídos às formas linguísticas, embora inseridos na mesma comunidade de fala em um sentido mais amplo.

Para além do conceito de comunidade, outras questões devem ser observadas para que a dinâmica do comportamento linguístico - individual e coletivo - seja capturada. Inúmeros estudos apontam para a diferença entre o papel das crianças e dos adultos nos processos de mudança, sugerindo que a idade seja um fator fundamental para análise da mudança em uma comunidade de fala. Eckert (1998) sugere que relacionar a variável 'idade' aos estudos linguísticos pressupõe a intersecção entre a vida do falante e a história da comunidade de fala em que ele se encontra inserido.

Ainda segundo Eckert (op. cit.), as instituições sociais desempenham um papel fundamental na transmissão de padrões linguísticos: crianças e adolescentes sofrem grande influência da escola e do processo de escolarização; adultos, por sua vez, sofrem grande pressão das regras de sociabilidade do mercado de trabalho; os mais velhos, em grande parte, estão fora do mercado de trabalho e têm o seu círculo social mais restrito. No mesmo sentido, Foulkes e Vihman (2013: 11) esclarecem que, durante a adolescência, os grupos sociais exercem um forte efeito sob os padrões linguísticos, sendo "as formas não-padrão transmitidas mais diretamente neste estágio da vida".

Eckert (op. cit.) sustenta ainda que, durante a adolescência, as mudanças linguísticas from bellow avançam, tendo em vista a necessidade de os adolescentes construírem uma identidade própria e, geralmente, em oposição à identidade de seus pais e/ou responsáveis. No entanto, é necessário retomar a ideia de que as condições socioeconômicas em que se encontram as famílias dos adolescentes funcionam como um importante mediador na construção da identidade dos sujeitos durante a adolescência, isto é, o nível socioeconômico das famílias e o acesso às instituições sociais colaboram sobremaneira na construção da identidade dos adolescentes. 
O comportamento linguístico dos adolescentes reflete não só a dinâmica social da comunidade de fala em que se encontram inseridos, mas também a influência das instituições sociais. Se, mesmo com a participação da escola, a adolescência é o período da vida dos falantes em que se verifica a maior possibilidade do desenvolvimento de formas linguísticas afastadas do padrão, seria de se esperar um aumento ainda maior de formas linguísticas não-padrão entre adolescentes que não frequentaram a escola e pertencem a classes sociais muito desfavorecidas. Situações de completa ruptura social podem comprometer a participação da escola e da família - ambas instituições sociais - na formação de identidades sociais, levando a uma outra conformação social e, consequentemente, linguística. Se as instituições sociais responsáveis pela transmissão de valores socialmente prestigiados estão ausentes na formação de sujeitos, novos valores e padrões podem ditar o comportamento linguístico desses sujeitos.

\section{As amostras}

Serão comparados dados obtidos a partir de três amostras da comunidade de fala do Rio de Janeiro: Amostra CENSO 2000, Amostra EJLA e Amostra Fiocruz. As três amostras, que integram o acervo do PEUL/UFRJ, representam dois grupos sociais distintos, com características socioeconômicas particulares. Para esta pesquisa, foram selecionados, dentre os falantes que compõem a amostra CENSO 2000, falantes que podem ser caracterizados como pertencentes a diferentes segmentos da classe média: não eram moradores de favelas, tinham acesso ao mercado formal de trabalho, concluíram o Ensino Fundamental e/ou Médio. Já as amostras EJLA e Fiocruz são constituídas por jovens moradores de favelas com diferentes graus de inserção social e acesso às instituições formadoras de padrões linguísticos e sociais. As diferentes características observadas para cada um dos dois grupos sociais refletem não só experiências sociais dos sujeitos que as compõem, mas também propiciam a formação de identidades sociais e comportamentos linguísticos igualmente distintos.

\subsection{Amostra CENSO 2000}

A Amostra CENSO 2000, composta por 32 (trinta e duas) horas de gravação e constituída entre os anos de 1999 e 2000, baseou-se nos mesmos parâmetros estratificadores da Amostra CENSO 1980, quais sejam: mesma segmentação de faixa etária (07 a 14, 15 a 25, 26 a 49 e acima de 50 anos), composta por falantes de 03 níveis de escolaridade (1ำ e $2^{\circ}$ ciclos do Ensino Fundamental e Ensino Médio), sexo masculino e feminino. Os falantes dessa amostra foram distribuídos aleatoriamente por diferentes bairros da cidade do Rio de Janeiro, a fim de garantir a mesma metodologia adotada na constituição da Amostra CENSO 1980. Para a presente pesquisa, foram selecionados 08 (oito) falantes ${ }^{4}$ pertencentes a diversos segmentos da classe média, os quais, muito embora possam não apresentar exatamente as mesmas características socioeconômicas (renda familiar), compartilham características comuns que os aproximam em termos sociais: todos os falantes selecionados tiveram acesso ao ensino formal e, em sua maioria, atuavam no mercado formal de trabalho.

\subsection{Amostra EJLA}

A Amostra EJLA, composta por 14 (quatorze) indivíduos, foi constituída entre os anos de 2008 e 2009. Todos os indivíduos que compõem a Amostra EJLA são do sexo masculino, tinham entre 14-20 anos e, à época das entrevistas, se encontravam cumprindo medida socioeducativa de internação em instituição pública do estado do Rio de Janeiro. Além de serem

${ }^{4}$ Falantes selecionados a partir da Amostra CENSO 2000: T07, T15, T18, T24, T06, T10, T13, T16 (cf. <www.letras.ufrj.br/peul>). 
moradores de favelas e de não terem acesso ao ensino formal, os falantes da EJLA advêm de famílias cujos vínculos afetivo-relacionais e referências de identificação são muito frágeis. Assim, em decorrência da situação de vulnerabilidade social em que se encontram, os falantes dessa amostra não atuam no mercado formal de trabalho e, em sua maioria, participam de facções criminosas com associação ao tráfico de drogas. Foram selecionados 08 (oito) falantes desta amostra para a presente pesquisa.

As entrevistas que constituem a amostra EJLA seguiram os princípios metodológicos de Labov (1972), a fim de que a amostra estivesse mais próxima ao uso dos falantes, fazendo com que eles se sentissem o mais à vontade possível, se esquecendo que estavam sendo observados. As gravações tiveram duração entre 30 e 60 minutos e foram realizadas com gravador digital, na própria unidade de internação onde os menores estavam internados.

\subsection{Amostra Fiocruz}

A amostra Fiocruz, composta por 24 (vinte e quatro) indivíduos, foi constituída entre os anos de 2010 e 2011. Compõem a amostra indivíduos de ambos os sexos (masculino e feminino), com idades entre 17 e 20 anos à época das entrevistas. Além disso, todos os indivíduos desta amostra estavam cursando o Ensino Médio em escolas da rede pública de ensino e, assim como os indivíduos da EJLA, eram moradores de comunidades pobres (favelas).

Utilizando a metodologia da entrevista sociolinguística, foram realizadas 24 (vinte e quatro) entrevistas, todas com tempo de duração entre 30 e 60 minutos, sendo que, para este artigo, foram analisadas 08 (oito) entrevistas. As entrevistas, gravadas com gravador digital, foram realizadas na Biblioteca da própria Fiocruz, local em que os jovens faziam o curso de monitor, em local reservado.
Importante destacar que, para realizar o curso, os jovens precisaram se submeter a um processo seletivo que incluía não só uma entrevista, mas também uma prova de produção textual (redação). Os jovens precisavam ter concluído o Ensino Fundamental e deveriam estar cursando, obrigatoriamente, o primeiro ano do Ensino Médio. 0 curso e as entrevistas do processo seletivo contavam com a participação de pesquisadores da Fiocruz, uma das instituições públicas de ensino e pesquisa mais renomadas nacionalmente e com projeção internacional na área de saúde pública. Destaca-se ainda que os jovens que compõem esta amostra ainda recebiam uma bolsa auxílio, a fim de garantir sua participação no curso, continuação dos estudos (na escola de origem) e evitar uma inserção antecipada no mercado de trabalho.

Além disso, os jovens que compõem a Amostra Fiocruz, apesar de serem moradores de favelas, não só são oriundos de famílias com vínculos afetivorelacionais mais estáveis, como também contam com o incentivo da família para continuarem seus estudos.

Podemos dizer que, embora compartilhem a mesma origem social - moradores de favela, de famílias de baixa renda - os adolescentes das amostras Fiocruz e EJLA tiveram diferentes encaminhamentos de suas vidas, muito provavelmente em razão de vínculos familiares mais estáveis e acesso a programas sociais: os adolescentes da amostra EJLA, na maioria das vezes, possuem vínculos familiares esgarçados ou frágeis, enquanto os adolescentes da amostra Fiocruz possuem vínculos familiares mais sólidos e estáveis; os adolescentes da amostra EJLA não tiveram acesso regular à educação formal, enquanto os adolescentes da Amostra Fiocruz tiveram acesso à educação formal (todos concluíram o Ensino Fundamental e, no momento das entrevistas, cursavam o Ensino Médio). Por essa razão foram aceitos em um programa social de uma importante instituição pública de ensino e pesquisa do país. 


\section{Análise de dados}

A variável em questão, variação de fricativas em coda, apresenta variantes com diferentes pontos de articulação tanto em coda interna quanto em coda em final de palavra, conforme mencionado anteriormente: alternância de realização como alveolar (de[z]de), pós-alveolar (de[3]de), realizações posteriores entre velar e glotal (de[h]de), aqui referidas como variante glotal, e ausência de realização do segmento (de[0]de). O envelope da variação excluiu os casos de ausência de coda que têm valor morfológico, como em "as pistola” (determinante 'a' + morfema de plural -s e nome pistola” sem marca de plural). Já a coda do determinante 'as' foi incluída e classificada como morfema, mas o zero de 'pistola' foi ignorado porque não tem relação com o objetivo do presente estudo, já que estudos sobre variação de realização de marca morfológica de plural no sintagma nominal têm mostrado que há a interferência de variáveis morfossintáticas, não se tratando exatamente de uma variável sonora (SCHERRE, 1988). Assim, somente os casos de ausência de coda exclusivamente relativos a codas não-morfêmicas foram incluídos, como em 'as dua $\emptyset$ '.

Os dados da Amostra Fiocruz foram submetidos ao programa Rbrul, da mesma maneira que os dados do estudo de Melo (2012) com dados da Amostra EJLA e da Amostra Censo 2000. As variáveis linguísticas consideradas foram aquelas já testadas por Melo (2012) para as amostras CENSO 2000 e EJLA, quais sejam: 'contexto seguinte', 'tamanho do item', 'status morfológico', 'posição da coda na palavra', 'tonicidade' e item lexical. Essas variáveis foram definidas em função do estudo de Gryner e Macedo (2000) sobre a variação das fricativas em coda com base em dados da Amostra Censo 1980. O foco da análise é a fricativa glotal realizada em posição de coda silábica. O que se pretende é estabelecer uma comparação entre os resultados obtidos para a nova amostra e aqueles já obtidos em Melo (2012) para os falantes da classe média selecionados a partir da amostra Censo 2000 e para os jovens excluídos socialmente que integram a amostra EJLA.

A Tabela 1 a seguir apresenta a distribuição das variantes por amostra. A comparação dos percentuais obtidos para as amostras em análise revela uma grande semelhança quanto à distribuição das variantes, em especial à realização da fricativa glotal, entre as Amostras CENSO 2000 e Fiocruz, 5\% e $6 \%$, respectivamente. Por outro lado, os resultados apontam uma grande diferença de ocorrência da variante glotal entre as duas amostras já citadas e a amostra EJLA, em que se verificou a ocorrência de $30 \%$ da variante glotal.

Tabela1 - Distribuição das variantes nas Amostras CENSO 2000, EJLA e Fiocruz

\begin{tabular}{lcccc}
\hline & {$[$ [j] / [3] } & {$[\mathbf{s}] /[\mathbf{z}]$} & {$[\mathbf{h}] /[\mathbf{f}]$} & $\emptyset$ \\
CENSO 2000 & 3949 & 1016 & $\mathbf{2 4 3}$ & 148 \\
Total = 5356 & $74 \%$ & $19 \%$ & $\mathbf{5 \%}$ & $3 \%$ \\
EJLA & 1517 & 349 & $\mathbf{8 5 0}$ & 125 \\
Total = 2841 & $53 \%$ & $12 \%$ & $\mathbf{3 0 \%}$ & $4 \%$ \\
FIOCRUZ & 2399 & 456 & $\mathbf{1 8 9}$ & 75 \\
Total = 3119 & $77 \%$ & $15 \%$ & $\mathbf{6 \%}$ & $2 \%$ \\
\hline
\end{tabular}

Inicialmente, esperava-se que, para os falantes da Amostra Fiocruz, a distribuição das variantes - sobretudo no que diz respeito à realização da fricativa glotal - estivesse mais próxima daquela observada para os indivíduos da EJLA. Isso porque os falantes das duas Amostras (EJLA e Fiocruz) são oriundos de favelas e têm, a princípio, uma formação social mais próxima se comparados aos falantes da classe média, o que pode ter reflexos nos valores sociais atribuídos às formas linguísticas por falantes do mesmo grupo social. No entanto, o que se observa é uma distribuição diferente, em que os falantes da Amostra Fiocruz apresentam um comportamento muito parecido com os falantes da classe média (Amostra CENSO 2000). 
Além disso, Melo (2012) observou que, para a amostra Censo 2000, os falantes menos escolarizados tendem a fazer uso significativamente maior da variante glotal (ensino fundamental incompleto, 10,4\%) do que os demais falantes (ensino fundamental completo, 2,4\%; e ensino médio completo, 3,1\%). Em outras palavras, a escolarização parece influenciar a realização da fricativa em coda: quanto mais escolarizado for o falante, menor será a probabilidade de realização da fricativa glotal. No entanto, o percentual de realização da variante glotal, obtido para os falantes de mais baixa escolaridade da Amostra Censo 2000, está distante dos 30\% obtidos para os falantes da Amostra EJLA.

Associada ao grau de escolarização dos falantes, também se observa, em alguns dos estudos realizados sobre a fricativa em coda em diversas variedades do português brasileiro, a referência ao estigma social negativo atribuído à realização da variante glotal, configurando-se a realização das variantes palatal ou alveolar como as de maior prestígio entre os falantes. Segundo Guy (1981), baixa frequência da glotal entre os falantes de diferentes níveis de escolaridade revela a avaliação negativa associada a esta variante. Gryner e Macedo (2000, p.44) atestam que a "variante inovadora prestigiada" (palatal) na região de Cordeiro é mais utilizada por falantes que atingiram grau de escolaridade mais elevado, ao passo que as variantes aspirada e zero constituiriam "formas mais populares", motivo pelo qual tenderiam a ser utilizadas por falantes menos escolarizados. Carvalho (2000, p. 107) observa que, entre os falantes de Belém (PA), a variante glotal é mais realizada entre falantes de classe mais baixa. Auler (1992, p. 51) sustenta que, no tocante à variedade da cidade do Rio de Janeiro, a variante glotal não constitui um "marcador dialetal diatópico", mas sim figura como "um indicador social" típico de falantes que estão menos sujeitos a pressões sociais em razão de seu comportamento linguístico.

Conforme já mencionado, as variáveis linguísticas observadas para a Amostra Fiocruz foram aquelas também observadas para as Amostras
CENSO 2000 e EJLA: 'contexto seguinte', 'tamanho da palavra', 'tonicidade', 'status morfológico', 'posição da coda na palavra' e item lexical ${ }^{5}$. As variáveis extralinguísticas seguiram as especificidades da Amostra: indivíduo e sexo. As variáveis 'grau de escolaridade' e 'idade', ambas observadas na análise da Amostra CENSO 2000, não foram analisadas, uma vez que todos os falantes tinham o mesmo grau de escolaridade e pertenciam à mesma faixa etária. A falante 'A' da amostra Fiocruz foi excluída da rodada, uma vez que ela não produziu nenhuma fricativa glotal. Além disso, fizeram parte da rodada apenas os itens com 03 ou mais ocorrências, ou seja, apenas aqueles itens que apresentaram algum tipo de variação, tendo sido excluídos os itens que ocorreram apenas 01 ou 02 vezes no corpus. 0 Quadro 1 abaixo mostra as variáveis observadas para as três Amostras.

Quadro 1 - Variáveis analisadas para as Amostras CENSO 2000, EJLA e Fiocruz

\begin{tabular}{|l|c|c|c|}
\hline \multirow{4}{*}{ Aplicação } & CENSO 2000 & EJLA & Fiocruz \\
\hline \multirow{4}{*}{ Variáveis } & $(\mathrm{h})$ & $(\mathrm{h})$ & $(\mathrm{h})$ \\
\cline { 2 - 4 } & contexto seguinte & contexto seguinte & contexto seguinte \\
\cline { 2 - 4 } & tamanho da palavra & tamanho da palavra & tamanho da palavra \\
\cline { 2 - 4 } & tonicidade & tonicidade & tonicidade \\
\cline { 2 - 4 } & status morfológico & status morfológico & status morfológico \\
\cline { 2 - 4 } & posição da coda & posição da coda & posição da coda \\
\cline { 2 - 4 } & indivíduo & indivíduo & indivíduo \\
\cline { 2 - 4 } & estilo de fala & estilo de fala & estilo de fala \\
\cline { 2 - 4 } & sexo & & sexo \\
\cline { 2 - 4 } & idade & & \\
\cline { 2 - 4 } & grau de escolaridade & & \\
\hline
\end{tabular}

${ }^{5}$ A escolha do Programa Rbrul para realização da análise estatística dos dados se deve à possibilidade de esta ferramenta poder incluir varía veis aleatórias, como item lexical juntamente com variáveis de esta ferramenta poder incluir variáveis aleatórias, como item lexical, juntamente com variáveis independentes. Variáveis aleatórias são aquelas cujos fatores são abertos e podem ter características coda e tamanho da palavra foram analisadas conjuntamente com a variável item lexical. 
Para os dados da Amostra EJLA, as variáveis selecionadas ${ }^{6}$ pelo programa foram indivíduo e item lexical e contexto seguinte (8.38e-54) + posição da fricativa em coda na palavra $(0.00213)$ + tonicidade da sílaba em que a fricativa em coda é realizada (0.0338). Importante esclarecer que às variáveis 'item lexical' e 'indivíduo' não são atribuídos p-valores, uma vez que essas variáveis são aleatórias (random effects), tendo em vista que características presentes nessas variáveis são também mapeadas por outras variáveis relativas a questões linguísticas (posição do segmento na palavra, tonicidade, contextos anterior e posterior etc) e aos sujeitos (no caso, o sexo dos falantes). As variáveis selecionadas para os dados da Amostra Censo 2000 foram falante + item lexical e contexto seguinte, status morfológico, tamanho do item lexical e estilo de fala. Para os dados da Amostra EJLA, as variáveis selecionadas foram item lexical + contexto seguinte, posição da sílaba na palavra, falante e estilo de fala. As variáveis comuns selecionadas pelo programa Rbrul para as três amostras (CENSO 2000, EJLA e Fiocruz) foram 'contexto seguinte', 'indivíduo' e 'item lexical'. Neste artigo, serão apresentados somente os resultados relativos às variáveis linguísticas comuns às três amostras e que fornecem evidências para a discussão do status da variação na organização do conhecimento linguístico do falante.

Os resultados para a variável linguística 'contexto seguinte' estão apresentados na Tabela 2 a seguir. De acordo com o quadro 01, o contexto seguinte é a variável independente sempre selecionada em primeiro lugar nas três amostras, o que releva a importância do condicionamento fonético na produção da variante glotal em final de sílaba.

${ }^{6}$ A relevância das variáveis selecionadas pelo Rbrul é observada em função do $p$-valor: quanto menor for o p-valor, maior será a significância da variável. Importante esclarecer ainda que "e-(número)" indica quantidade de casas decimais atribuídas a um determinado p-valor, ou seja, "e-10" indica que este p-valor é composto por 10 casas decimais que são 0 e a partir daí aparecem os demais algarismos (por o p-valor e, portanto, maior será a significância de determinada variável.
Tabela 2 - Realização da variante glotal em função do contexto seguinte nas Amostras CENSO 2000, EJLA e Fiocruz

\begin{tabular}{|c|c|c|c|c|c|c|c|c|c|}
\hline \multirow{2}{*}{ Variante } & \multicolumn{3}{|c|}{ CENSO 2000} & \multicolumn{3}{|c|}{ EJLA } & \multicolumn{3}{|c|}{ Fiocruz } \\
\hline & Apl/N & $\%$ & Peso & Apl/N & $\%$ & Peso & $\mathrm{Apl} / \mathrm{N}$ & $\%$ & Peso \\
\hline Consoante soante & $157 / 735$ & 21,4 & 0,961 & $413 / 472$ & 87,5 & 0,988 & $68 / 262$ & 27,5 & 0,927 \\
\hline Obstruinte vozeada & $71 /$ & 9,1 & 0,899 & $271 / 336$ & 83,3 & 0,965 & $96 / 315$ & 31,3 & 0,875 \\
\hline Obstruinte desvozeada & $12 / 2160$ & 0,6 & 0,290 & $153 / 1245$ & 11,7 & 0,381 & $181 / 1179$ & 1,5 & 0,314 \\
\hline Vogal & $1 / 972$ & 0,1 & 0,045 & $5 / 339$ & 1,5 & 0,029 & $3 / 403$ & 0,2 & 0,024 \\
\hline Pausa & $2 / 561$ & 0,4 & 0,191 & $5 / 300$ & 1,3 & 0,023 & - & - & - \\
\hline
\end{tabular}

Os resultados obtidos em Melo (2012) para a Amostra Censo 2000 e EJLA, comparados aos obtidos para a Amostra Fiocruz, indicam que a glotal tende a ocorrer antes de consoantes soantes e vozeadas, o que indica que a glotal é favorecida em contexto sonoro, ao passo que é fortemente desfavorecida quando seguida de consoante desvozeada, vogal e pausa. Verifica-se, portanto, o mesmo condicionamento fonético para a variante glotal nas três amostras, resultado esperado, uma vez que a motivação fonética de uma variação envolve características dos sons e relações entre eles que decorrem de um mesmo aparato físico compartilhado por todos os falantes da comunidade de fala. Conforme assinalado em Melo (2012), o fato de a realização da glotal ser favorecida quando a coda é seguida por consoante soante ou obstruinte sonora se deve, provavelmente, à mesma configuração que as cordas vogais assumem durante a produção da fricativa glotal e de consoantes vozeadas.

Conforme mencionado anteriormente, a variável 'item lexical' foi selecionada para as três amostras (CENSO 2000, EJLA e Fiocruz), confirmando a importância de se analisar os efeitos do item lexical para a variação da fricativa em coda. Ressalta-se que a variável 'item lexical' encerra diferentes características que não estão sendo mapeadas neste momento, as quais podem 
estar concorrendo para a realização da fricativa em coda, como, por exemplo, a frequência de ocorrência do item. Em Melo (2012, p. 93), há evidências de que a frequência do item contribui para a realização das variantes de fricativa em coda nos dados coletados da Amostra EJLA, isto é, a variante glotal tende a ocorrer nos itens com maior frequência de ocorrência. No entanto, a partir da observação do comportamento de itens mais frequentes nas três amostras - EJLA, Fiocruz e CENSO 2000, observam-se realizações distintas desses itens nas amostras: a variante glotal não constitui a variante mais frequente para os itens mais frequentes na amostra CENSO 2000 e na Amostra Fiocruz, uma vez que nenhum dos itens apresentados é realizado predominantemente com a glotal; por outro lado, na amostra EJLA, observa-se uma ocorrência muito superior da glotal para os mesmos itens mais frequentes, sendo alguns itens - como mesmo - realizados com predominância da variante glotal.

A Tabela 3 a seguir apresenta alguns dos itens observados nas amostras. Constam da tabela os itens com maior frequência de ocorrência nas três amostras para efeito da comparação.

Tabela 3 - Realização da fricativa glotal em função do item lexical nas Amostras CENSO 2000, EJLA e Fiocruz

\begin{tabular}{|c|c|c|c|c|c|c|}
\hline \multirow{2}{*}{ Itens } & \multicolumn{2}{|c|}{ CENSO 2000} & \multicolumn{2}{|c|}{ EJLA } & \multicolumn{2}{|c|}{ Fiocruz } \\
\hline & Apl/N & $\%$ & Apl/N & $\%$ & Apl/N & $\%$ \\
\hline mais* & $44 / 332$ & 13,30 & $52 / 108$ & 48,14 & 8/187 & 15,50 \\
\hline mas & $32 / 461$ & 6,90 & $65 / 144$ & 45,13 & $33 / 223$ & 14,80 \\
\hline às vezes & $0 / 141$ & 0,00 & $81 / 85$ & 95,30 & $17 / 67$ & 12,50 \\
\hline eles & $8 / 234$ & 3,40 & $23 / 124$ & 21,30 & $11 / 72$ & 8,30 \\
\hline nós & $7 / 34$ & 20,60 & $137 / 235$ & 58,29 & $3 / 10$ & 3,00 \\
\hline mesmo & $41 / 279$ & 14,70 & $113 / 127$ & 89,00 & $1 / 49$ & 2,00 \\
\hline
\end{tabular}

*Embora a conjunção mas e o advérbio mais tenham sido contabilizados separadamente, na comunidade de fala do Rio de Janeiro, esses dois itens ocorrem predominantemente com a mesma variabilidade.
Observa-se o comportamento diferenciado dos itens lexicais na mesma amostra, uma vez que apresentam diferentes percentuais de ocorrência com a glotal. A comparação dos percentuais dos mesmos itens nas três amostras indica que a ocorrência com a glotal é mais frequente nos itens produzidos pelos falantes da Amostra EJLA, com índices superiores aos obtidos nas outras duas amostras. O comportamento dos falantes das amostras CENSO 2000 e Fiocruz tende a convergir para a maioria dos itens. Observa-se também que alguns itens-lexicais são realizados predominantemente com a fricativa glotal entre os falantes da Amostra EJLA (às vezes - somente o determinante, mesmo e nós). É interessante observar que no chunck às vezes, que apresenta o contexto altamente favorecedor da glotal para o item às, coda seguida de consoante sonora, o comportamento é diferente nas três amostras. A realização da glotal é semicategórica entre os falantes da Amostra EJLA, tem baixa realização entre os falantes da Amostra FIOCRUZ e está ausente entre os falantes da Amostra CENSO 2000. A coda da palavra vezes não foi considerada nesta análise porque este item do chunck aparece quase que invariavelmente no singular nos dados da amostra EJLA.

A seleção das variáveis explicativas pelo Programa Rbrul revelou que tanto o condicionamento fonético relativo ao contexto seguinte quanto o item lexical são importantes na dinâmica da variação da fricativa em coda, sendo condicionamentos que competem para a realização das variantes e não são excludentes entre si, isto é, não se trata de uma variável sonora que ou apresenta condicionamento fonético ou apresenta condicionamento lexical. Bybee (2002, p.244) observa que a visão dicotômica verificada na literatura, relativa à divisão entre mudanças do tipo neogramático, estritamente condicionadas por variáveis estruturais, e mudanças do tipo difusão lexical, sem condicionamento fonético e com condicionamento lexical (WANG, 1969; LABOV, 1981, 1994), reflete uma visão de gramática segundo a qual as representações abstratas são fonêmicas e a mudança só 
ocorre se houver substituição de fonema. As evidências que apontam que há mudanças que apresentam tanto gradualidade fonética quanto lexical contribuem para o estabelecimento de uma nova hipótese de representação que inclui o detalhe fonético na representação das palavras no léxico e que estabelece uma relação de continuidade entre léxico e gramática, como postulado nos Modelos baseados no Uso.

O comportamento diferenciado dos falantes das três amostras, observado para os mesmos itens lexicais, portanto, pode ser interpretado à luz das hipóteses dos Modelos baseados no Uso, mencionadas na seção 2. De fato, o comportamento diferenciado dos itens lexicais coloca problemas para a noção de variação como regra. Como explicar a diferença de "aplicação" da regra em cada amostra para o mesmo item lexical? Assim, a adoção da hipótese de status representacional da variação permite interpretar o percentual de realização das variantes como indicativa da representação mais robusta de determinada variante na nuvem de exemplares. Dessa forma, para os falantes da amostra EJLA, a representação mais robusta é com a variante glotal para determinados itens, ao passo que, para os falantes das amostras Censo 2000 e Fiocruz, a representação central seria com a pós-alveolar para os mesmos itens. Essas diferenças representacionais podem ser também tomadas como diferentes padrões de representação que são indicativos de diferentes direcionalidades de propagação das variantes na comunidade de fala do Rio de Janeiro.

\section{Considerações finais}

O presente artigo apresentou resultados de pesquisa que focalizou grupos sociais distintos da comunidade de fala do Rio de Janeiro: falantes da classe média, selecionados dentre os falantes que compõe a amostra Censo 2000; adolescentes, moradores de favelas que, em graus diferentes, tem menor acesso às instituições formadoras e transmissoras de padrões sociolinguísticos. Esse último grupo de falantes está representado por duas diferentes amostras: Amostra EJLA e Amostra Fiocruz, constituída por jovens moradores de favela que possuíam algum tipo de inserção em programa social de instituição pública do Rio de Janeiro. Apesar de serem jovens moradores de favela, os falantes da Amostra Fiocruz, diferentemente dos jovens da Amostra EJLA, apresentam algum grau de inserção social, tendo em vista que apresentam um processo regular de escolarização e frequentavam um curso para monitores de museus, oferecido por uma das maiores instituições de ensino e pesquisa do país.

Por fim, a comparação dos resultados obtidos para as três amostras indicou que:

a) não há incompatibilidade entre efeito de condicionamento fonético e lexical na variação, uma vez que ficou evidenciada a importância de ambos os condicionamentos;

b) o comportamento diferenciado dos falantes da Amostra EJLA, expresso na taxa global de realização da fricativa glotal e na realização de itens com predominância desta variante, revela que pode haver diferentes direcionalidades de mudança na comunidade de fala. A modelagem dos MBU permite capturar esse fato, uma vez que, neste modelo, a variação tem status representacional. Em um modelo que captura a variação como um processo que se aplica a uma representação subjacente única, gerando diferentes outputs, não é possível verificar o comportamento diferenciado para os mesmos itens lexicais na comunidade de fala. A representação da variação nos moldes da Teoria de Exemplares permite afirmar que os percentuais mais altos de realização do item com a glotal expressam representações com diferentes centralidades, sendo, por exemplo, a representação de mesmo e da coda no chunck às vezes mais robusta com a glotal 
para os falantes da Amostra EJLA e com a fricativa pós-alveolar para os demais falantes das outras duas amostras. Esse resultado avança o entendimento inicial do estudo de Gryner e Macedo (2000, p.62) segundo o qual os resultados obtidos para a variante glotal "evidenciam influências lexicais, ao lado de fortes influências fonológicas. Isto indica necessidade de análises futuras que levem em conta, por exemplo, frequência e formalidade dos itens";

c) em relação ao comportamento dos falantes por Amostra, o que se observou foi o contrário do que se esperava, isto é, os falantes da Amostra Fiocruz apresentaram um comportamento semelhante ao dos falantes da amostra Censo 2000, mostrando que o grau de inserção social é relevante para o comportamento dos falantes. Conforme apresentado, a realização da fricativa glotal parece ser evitada por falantes mais escolarizados. Assim, é possível que, devido a um processo de escolarização mais regular e à maior inserção social dos falantes da Amostra Fiocruz, os falantes dessa amostra tenham mais contato com variantes de prestígio, participando de situações sociais em que se faz necessário um maior monitoramento da fala. Por esse motivo, os falantes da Amostra Fiocruz parecem evitar o uso de algumas variantes estigmatizadas, tais como a fricativa glotal;

d) ainda, para os mesmos itens lexicais observados na Tabela 3, a comparação do comportamento dos itens nas três amostras mostra a predominância da variável social, expressa aqui em função das características sociais dos três grupos de falantes das três amostras, sobre a variável estrutural ambiente seguinte, uma vez que, mesmo no ambiente altamente favorecedor de ocorrência da glotal, seguida de consoante soante ou obstruinte vozeada, a realização como glotal foi muito baixa ou inexistente na Amostra Censo e na Fiocruz. Em outras palavras, itens mais frequentes em contextos favoráveis à realização da fricativa glotal são realizados de maneiras distintas pelos grupos de falantes. Há uma predominância da variante glotal em itens de alta frequência e nos quais se observa o condicionamento fonético favorável à glotal para os falantes da Amostra EJLA, enquanto, para os falantes da Amostra CENSO 2000 e Fiocruz, para os mesmos itens, a glotal foi a variante menos realizada.

As diferenças e semelhanças observadas entre os falantes das três amostras podem conduzir à conclusão de que os indivíduos de uma mesma comunidade de fala não compartilham os mesmos valores e, por conseguinte, não fazem as mesmas avaliações das formas linguísticas. Se os falantes de uma mesma comunidade de fala partissem de uma mesma avaliação sobre as formas linguísticas, como explicar que falantes de um mesmo grupo social tenham comportamentos distintos em relação à mesma variável? Tudo indica que as instituições responsáveis pela formação dos sujeitos atuam fortemente no comportamento linguístico desses sujeitos. Também ficou evidenciada a importância do item lexical para a realização da variável.

\section{Referências}

AULER, Mônica. A difusão lexical num fenômeno de aspiração em português. In: Revista de Estudos da Linguagem, Belo Horizonte, Faculdade de Letras da UFMG, 1992.

BIRMAN, Patrícia. “Favela é comunidade?”. In: SILVA, Luiz Antônio Machado da (Org.). Vida em cerco: violência e rotina nas favelas do Rio de Janeiro. Rio de Janeiro: Nova Fronteira, 2008.

BRESCANCINI, Cláudia R. A palatalização da fricativa alveolar não-morfêmica em posição de coda no português de influência açoriana do município de Florianópolis: uma abordagem não-linear. 1996. Dissertação (Mestrado em Letras) - Universidade Federal de Santa Catarina, Florianópolis, 1996.

BYBEE, Joan. Phonology and language use. Cambridge: Cambridge University Press, 2001. https://doi.org/10.1017/CB09780511750526 
BYBEE, Joan. Word frequency and context of use in the lexical diffusion of phonetically conditioned sound changes. Language Variation and Change, v. 14, p. 261-290, 2002.

BYBEE, J. Language, usage and cognition. Cambridge: Cambridge University Press, 2010.

BYBEE, Joan. Patterns of lexical diffusion and articulatory motivation for sound change. In: SOLÉ, Maria-Josep; RECASENS, Daniel (Ed.). The initiation of sound change: perception, production and social factors. Amsterdam and Philadephia: John Benjamins Publishing Co. p. 211-234, 2012

CALLOU, Dinah I.; BRANDÃO, Silvia F. Sobre o /s/ em coda silábica no Rio e Janeiro: falas culta e popular. In: SALGADO, Ana Claudia Peters; BARRETTO, Mônica M. Guimarães Savedra (Org.). Sociolinguística no Brasil: uma contribuição dos estudos sobre línguas em/ de contato: homenagem ao Prof. Jürgen Heye. Rio de Janeiro: 7 Letras, 2009. p. 27-34.

CALLOU, Dinah I.; MARQUES, Maria Helena D. O -s implosivo na linguagem do Rio de Janeiro. Littera, n. 14, p. 9-137, 1975.

CALLOU, Dinah I.; MORAES, João A. de. A norma de pronúncia do S e R pós-vocálicos: distribuição por áreas regionais. In: CARDOSO, Suzana A. M. (Org.). Diversidade lingüística e ensino. Salvador: EDUFBA, 1996. p. 133-147.

CANOVAS, Maria I. F. Variação fônica de /S/ pós-vocálico e de /v, z, 3/ cabeças de sílaba, na fala de Salvador. Dissertação (Mestrado em Língua Portuguesa) - Programa de Pós-Graduação em Letras, Universidade Federal da Bahia, Salvador, 1991.

CARVALHO, Rosana Siqueira de. Variação do /S/ pós-vocálico na fala de Belém. Dissertação (Mestrado) - Programa de Pós-Graduação em Linguística, Universidade Federal do Pará, 2000.

DOCHERTY, Gerard J.; FOULKES, Paul. An evaluation of usage-based approaches to the modelling of sociophonetic variability. Lingua, v. 142, p. 42-56, 2014. https://doi. org/10.1016/j.lingua.2013.01.011

ECKERT, Penelope. Age as a sociolinguistic variable. In: COULMAS, Florian (Ed.). The Handbook of Sociolinguistics. Malden, MA/Oxford: Blackwell, 1998. p. 151-167.

FOULKES, Paul; DOCHERTY, Gerard J. The social life of phonetics and phonology. Journal of Phonetics, v. 34, p. 151-167, 2006.

FOULKES, Paul; VIHMAN, Marilyn. Language acquisition and phonological change. In: HONEYBONE, P.; SALMONS, J. C. (Ed.). The Handbook of Historical Phonology. Oxford University Press, 2013
GOMES, Christina A. Para além dos pacotes estatísticos VARBRUL/GOLDVARB e RBRUL: qual a concepção de gramática? Revista do GELNE, v. 13, n. 1, p. 259-272, 2011.

GOMES, Christina A.; PAIVA, Maria da Conceição de. Variação no grupo, no indivíduo e relação implicacional entre variáveis linguísticas. Veredas, Editora da UFJF, Juiz de Fora, v. 11, n. 1, p. 105-113, 2002.

GOMES, Christina A.; SILVA, Thais C. Variação linguística: questão antiga e novas perspectivas. Lingua(gem), ILAPEC/Macapá, v. 1, n. 2, p. 31-41, 2004.

GRYNER, Helena; MACEDO, Alzira V. T. A pronúncia do -S pós-vocálico na região de Cordeiro - RJ. In: MOLLLICA, Maria Cecilia; MARTELOTTA, Mário Eduardo (Org.). Análises linguísticas: a contribuição de Alzira Macedo. Rio de Janeiro: Serviço de Publicações -FL/UFRJ, 2000. p. 26-51.

GUY, Gregory R. Linguistic Variation in Brazilian Portuguese: aspects of the phonology, syntax, and language history. PhD Dissertation. University of Pennsylvania, 1981.

GUY, Gregory R. As comunidades de fala: fronteiras internas e externas. In: CONGRESSO INTERNACIONAL DA ABRALIN, II., Fortaleza, março de 2001. Anais do ... Fortaleza, 2001.

HINSKENS, Frans; BERMANS, Ben; OOSTENDORP, Marc van. Grammar or lexicon or grammar and lexicon? Rule-based and usage-based approaches to phonological variation. Lingua, v. 142, p. 1-26, 2014. https://doi.org/10.1016/j.lingua.2014.01.005

JOHNSON, Keith. Speech perception without speaker normalization. In: JOHNSON, K.; MULLENNIX (Ed.). Talker Variability in Speech Processing. San Diego. Academic Press, 1996.

LABOV, William. Sociolinguistic Patters. Philadelphia: University of Pennsylvania Press, 1972.

LABOV, William. Resolving the neogrammarian controversy. Language, 57, p. 267-308, 1981. https://doi.org/10.2307/413692

LABOV, William. Principles of Linguistic Change: Internal factors. Oxford: Blackwell Ed 1994.

MACEDO, Sandra S. A palatalização do /s/ em coda silábica no falar culto recifense. Dissertação (Mestrado em Linguística) - Universidade Federal de Pernambuco, Recife, 2004.

MELO, Marcelo A. S. L. Desenvolvendo novos padrões na comunidade de fala: um estudo sobre a fricativa em coda na comunidade de fala do Rio de Janeiro. Dissertação (Mestrado) - Programa de Pós-Graduação em Linguística, Universidade Federal do Rio de Janeiro, 2012 
MOTA, J. A. $O<s>$ em coda silábica na norma culta de Salvador. 2002. Tese (Doutorado em Língua Portuguesa) - Faculdade de Letras, Universidade Federal do Rio de Janeiro, Rio de Janeiro, 2002.

NARO, Anthony J.; SCHERRE, Maria Marta P. Variação e mudança linguística: fluxos e contrafluxos na comunidade de fala. Cadernos de Estudos Linguísticos, v. 20, Campinas, UNICAMP/IEL. 1991. p. 9-16.

PAIVA, Maria da Conceição de. A variável gênero/sexo. In: MOLLICA, Maria Cecília; BRAGA, Maria Luiza (Org.). Introdução à Sociolinguística - o tratamento da variação. São Paulo: Contexto, 2003. p.33-42.

PAIVA, Maria da Conceição de; DUARTE, Maria Eugênia L. Introdução: a mudança lingüística em curso. In: PAIVA, Maria da Conceição de; DUARTE, Maria Eugênia L. (Org.). Mudança linguística em tempo real. Rio de Janeiro: Contra Capa, 2003. v. 1. p. 13-29.

PATRICK, Peter L. The Speech Community. In: CHAMBERS, J. K.; TRUDGILL, P.; SCHILLINGESTES, N. (Ed.). The Handbook of Language Variation and Change. Oxford: Blackwell Publishing, 2002. p. 573-597.

PIERREHUMBERT, Janet B. Probabilistic Phonology: discrimination and robustness. In: BOD, Rens; HAY, Jennifer, JANNEDY, Stefanie (Ed.). Probability Theory in Linguistic. The MIT Press, Cambridge MA, 2003. p. 177-228.

PIERREHUMBERT, Janet B. Phonological representation: Beyond abstract versus episodic. Annual Review of Linguistics, v. 2, p. 33-52, 2016. https://doi.org/10.1146/ annurev-linguistics-030514-125050

RONCARATI, Cláudia N. Variação fonológica e morfossintática na fala cearense. In: JORNADA DE ESTUDOS LINGUÍSTICOS DO GELNE, 17., 1999, Fortaleza. Anais... Fortaleza: UFC, 1999. p. 1-12.

SANTOS, Deisiane R. dos. A Variação do /S/ pós-vocálico fa fala de Petrópolis, Itaperuna e Paraty. Dissertação (Mestrado em Linguística) - Faculdade de Letras, Universidade Federal do Rio de Janeiro, Rio de Janeiro, 2009.

SCHERRE, Maria Marta P. Reanálise da Concordância Nominal em Português. Tese (Doutorado em Linguística) - Faculdade de Letras, Universidade Federal do Rio de Janeiro, Rio de Janeiro, 1998.

SCHERRE, Maria Marta Pereira; MACEDO, Alzira V. T. Restrições fonético-fonológicas e lexicais: o -S pós-vocálico no Rio de Janeiro. In: MOLLICA; Maria Cecília; MARTELOTTA,
Mário Eduardo T. (Org.). Análises linguísticas: a contribuição de Alzira Macedo. Rio de Janeiro: Serviço de Publicações - FL/UFRJ, p. 52-64, 2000.

WEINREICH, Uriel; LABOV, William; HERZOG, Marvin. Empirical Foundations of a Theory of Language Change. In: LEHMANN, Winfred P.; MALKIEL, Yakov (Ed.). Directions for Historical Linguistics. Austin: University of Texas, 1968, p. 97-195.

WANG, William S.-Y. Competing changes as a cause of residue. Language, v. 45, p. 9-25, 1969. https://doi.org/10.2307/411748

Recebido em 20/08/2016

Aceito em 13/01/2017. 